\title{
De grandes ombres
}

\section{Yves Bonnefoy}

\section{(2) OpenEdition}

Journals

Édition électronique

URL : https://journals.openedition.org/rbnu/3500

DOl : $10.4000 /$ rbnu.3500

ISSN : 2679-6104

\section{Éditeur}

Bibliothèque nationale et universitaire de Strasbourg

\section{Édition imprimée}

Date de publication : 1 mai 2011

Pagination : 84-85

ISSN : 2109-2761

\section{Référence électronique}

Yves Bonnefoy, «De grandes ombres », La Revue de la BNU [En ligne], 3 | 2011, mis en ligne le 01 mai

2011, consulté le 08 août 2021. URL : http://journals.openedition.org/rbnu/3500 ; DOI : https://

doi.org/10.4000/rbnu.3500

\section{(c) (i) (3)(2)}

La Revue de la BNU est mise à disposition selon les termes de la Licence Creative Commons Attribution - Pas d'Utilisation Commerciale - Partage dans les Mêmes Conditions 4.0 International. 


\section{DE GRANDES OMBRES}

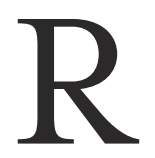

emarquable l'art de ce peuple très ancien dont nous contemplons les œuvres dans ces salles nous ne savons si de cavernes ou de musées. Ce sont de toute évidence des formes d'hommes, de femmes, mais avec des élongations excessives des bras, le long des corps ou projetés vers le haut, et aussi des mains qui semblent se distendre, se dilater, s'agiter, pour ne rien dire des têtes, dont quelques-unes semblent surmontées de ces immenses bois qu'on voit chez les cerfs quand ils vieillissent. Et tout dans ces figures, d'un bord à l'autre de leur contour aux si bizarres découpes, de la même couleur bleu sombre.

Mais ne vous étonnez pas, m'explique-t-on, ces dévots du soleil couchant ne s'intéressaient quà leurs ombres qui s'étendaient devant eux sur le sable fin de leurs plages ou l'herbe de leurs prairies. Ils se réunissaient le soir, quand le soleil déclinait vers l'horizon, bientôt à le toucher presque ; et tournés vers l'orient où ce même soleil devrait, ils l'espéraient, reparaître, ils regardaient devant eux s'éployer leurs ombres, maintenant beaucoup plus longues qu'euxmêmes ils n'étaient hauts. Leur désir ? En remuant leurs bras ou leurs mains d'échanger des signes, à la cime comme orageuse de ces prolongements de leurs corps ; et, en somme, là-bas, de se parler, mieux qu'ici, en poussant vers les ombres d'autres qu'euxmêmes une partie de la leur, par exemple ces doigts, parfois écartés, qui devenaient, le soleil baissant, fantastiques : une sorte d'oiseau dont l'aile touchait, oh, délicatement, modestement, une épaule, voire une nuque. Leur vie ? C'était là-bas, oui, là-bas, aux confins de la lumière de plus en plus rouge du ciel et de la terre paisible, qu'elle se jouait : pas ici, où ils ne portaient guère intérêt à leurs occupations ordinaires, y vaquant parce qu'il le fallait bien, mais levant souvent les yeux de leurs travaux du moment pour s'adresser les uns aux autres des regards, des sourires de connivence. Les heures passaient, en effet, le ciel changeait, bientôt ce serait l'heure de quitter les champs, de sortir des maisons aux miroirs voilés, de dépasser les derniers grands arbres de la route, pour aller côte à côte jusqu'en terrain découvert et, là, tenter de se dire, à bonne distance, toutes les belles choses qu'ils avaient méditées pendant la journée.

Car c'était un peuple heureux, me dit-on encore. Les velléités de discussion, de dispute, les agacements, les jalousies, auraient-ils voulu s'exprimer, se faire pensée consciente, ils se seraient vite évaporés dans ce qu'avait de léger, de doux, de dansant, le zigzag de l'ombre du bout des bras tendus au-dessus des têtes ou tournés vers des corps consentants ou se 
dérobant, ou mus quelquefois, en des mouvements assez malaisés à comprendre, par le désir, semblait-il, d'atteindre tel rocher qui sortait de l'herbe, très loin pourtant, de l'effleurer, le toucher. Le toucher ? Ou bien même le saisir, ombre, fruit d'ombre que cette pierre elle aussi était devenue, au creux de la nuit qui tombait ? - Pas nécessairement, à vrai dire. Un observateur, s'il y en avait eu un dans ces temps et dans ces pays, aurait pu remarquer en tel ou tel de ces gestes autre chose que l'anxiété heureuse du contact qui s'établit presque, se perd, va tout de même avoir lieu : plaisir du jeu, jouissance de soi, bonheur d'une existence qui prend conscience d'une autre, dans la lumière. Il aurait perçu, ces fois-là, en fait assez rares, un frémissement, de la fébrilité, une hâte à s'emparer de l'autre ombre qui pouvait signifier la crainte d'un peu de déception, voire d'un instant de tristesse, quand cette main désirante se serait unie à l'objet de son vœu mais, en somme, rien qu'en image.

Métaphysique, certes, cette inquiétude ; et en grand péril de spéculation métaphysique ces hommes et ces femmes qui ne s'animaient vraiment qu'à l'heure où bientôt ce serait la nuit. D'abord, à ne penser ainsi qu'au soleil du soir, il fallait bien que pendant tout le jour ils eussent été silencieux, n'échangeant de propos que pour que la vie continuât sans trop de soucis et de fatigues. Puis il y avait les enfants qui, c'était étonnant, ne comprenaient pas l'intérêt de ces départs de la fin d'après-midi. Non qu'ils ne prissent plaisir, eux aussi, à jouer avec leurs ombres, quand ils arrivaient sur le grand rebord. Ils faisaient toutes sortes de gestes, ils gambadaient, ils riaient. Mais ils couraient partout, se cachaient derrière leurs parents, s'amusaient à grossir l'ombre de ceux-ci, qui n'avait que faire de leur petite vie dans ses jambes, et ils s'exclamaient, ils criaient. Ils se fatiguaient, aussi bien, allaient s'asseoir à l'écart, se faisaient porter, sur le chemin du retour, ne pensant plus qu'au repas qu'ils feraient bientôt devant le feu de la cheminée, aux ombres dansantes sur les dalles de la cuisine.

Les enfants sont-ils en plus et peut-être en trop dans une poétique des ombres ? D’autres observateurs se demandaient si ces célébrants de l'ombre portée n'étaient pas motivés par une idée du théâtre. Par le sentiment que là-bas, aux confins de la terre et du ciel, dans le débat de l'herbe encore ensoleillée et de ces silhouettes déjà un peu averties de la nuit,

commençait peut-être de trouver forme - de prendre sens - un drame qui jamais ne pourrait s'expliciter ici, parmi nous, son action échappant aux catégories du langage. Ces observateurs - ces critiques - imaginent que les participants de ces jeux, en fait des rites, se parleront, tout de même, la nuit venue, la maison retrouvée, voire même le feu éteint ou tout au moins réduit à rien que des braises dans l'âtre noir, avec de temps en temps de brusques petites flammes. Ils sont serrés les uns contre les autres, dans la pénombre des chambres, ils se tiennent la main, ils rient, quelquesuns, brièvement, ils évoquent, à mots couverts, Dieu sait quel événement qu'un parmi eux aurait cru voir s'ébaucher sur les hauts tréteaux de leur scène de chaque soir. Et ils tentent de le comprendre, cet événement, ils s'en émeuvent, ils espèrent. Hélas, il y a aussi dans le sommeil qui les gagne des voix pour les inciter à désespérer.

Que se demandent-ils ? Si, parmi leurs ombres là-bas une ombre en plus ne s'était pas glissée, ce jour-là, mais hier aussi, et peut-être encore d'autres fois ? Une ombre qui leur ressemblait, les mêmes mains dilatées au bout d'un même corps distendu, mais non, ce n'était ni toi, ni moi, ni lui, ni elle, et d'ailleurs il n'avait paru qu'un instant, cet en plus, peut-être homme peut-être femme, peut-être, qui sait, bête mystérieuse, cervidé ? Un instant, seulement un instant? Mais le temps, ce soleil qui baissait, n'avaitil pas hésité alors, ne croyez-vous pas, ne crois-tu pas, comme s'il s'était mis à réfléchir, pataugeant dans ces flaques d'ombres et de lumières, imaginant, quels nouveaux ciels, quels nouveaux horizons, de s'arrêter dans sa course ? Illusions, certes, mirages de la distance, ces impressions fugitives. Mais si, demain, cet instant revenait et, cette fois... ? On discute de cela, les heures de la nuit se précipitent dans l'estuaire de l'aube, le soleil va se lever, la journée reprendre. L'art - de vastes tableaux d'apparence toute sereine naît dans une de ces maisons, celle dont l'âtre n'en finit pas, pour quelque raison, de jeter des ombres de bêtes et d'enfants sur les dalles claires.

\section{Yves Bonnefoy}

